\title{
Family Supportive Supervisor Behaviors and Family-Like Employee-Organization Relationship: Effects on Employees Organizational Citizen Behavior
}

Jie Lv

School of Business Administration, South China University of Technology, Guangzhou, China

Email: scutlj@126.com

How to cite this paper: Lv, J. (2018) Family Supportive Supervisor Behaviors and Family-Like Employee-Organization Relationship: Effects on Employees Organizational Citizen Behavior. Open Journal of Business and Management, 6, 400-411. https://doi.org/10.4236/ojbm.2018.62029

Received: March 24, 2018

Accepted: April 24, 2018

Published: April 27, 2018

Copyright $\odot 2018$ by author and Scientific Research Publishing Inc. This work is licensed under the Creative Commons Attribution International License (CC BY 4.0).

http://creativecommons.org/licenses/by/4.0/ (c) (i) Open Access

\begin{abstract}
The present study developed a mediation model to examine how family supportive supervisor behaviors (FSSB) affect employees' family-like employee-organization relationship (FEOR) which in turn affects employees' organizational citizen behavior (OCB). A random sample of 211 Chinese fulltime employees completed online surveys, and to test the former assumptions M-plus software was used to conduct linear regression analysis. Results shows: 1) family supportive supervisor behaviors are positively related to family-like employee-organization relationship, 2) family-like employee-organization relationship is positively related to employees' organizational citizen behavior, and 3) the relationship between FSSB and OCB was partly mediated by FEOR.
\end{abstract}

\section{Keywords}

Family Supportive Supervisor Behaviors, Family-Like Employee-Organization Relationship, Organizational Citizen Behavior

\section{Introduction}

During the last decades, enterprises have been confronted with a more diverse environment of competition; the geographic limitation has been broken by the globalization. With the rise of Electronic Commerce, competition pressure is unprecedented. Thus, organizations are more dependent than ever on employee performance as a source of sustained competitive advantage which requires employee's extra effort. Under this circumstance, employee is burdened more tasks and faced more challenges than ever. Consequently, employees desired organi- 
zational support which became a hot topic in academia. Based on the prior research, formal organizational support policies are expensive to implement and employees tend to be reluctant to use them because of concerns about the career penalties associated with their use [1]. Employee turned to informal support which is more flexible and accessible than formal support to reduce work-family conflict [2]. Hammer et al., (2009) contend a specific type of informal supervisor support-FSSB beyond formal organizational support. FSSB is conceptualized as a multidimensional super ordinate construct with four subordinate dimensions: emotional support, instrumental support, role modeling behaviors, and creative work-family management [3]. Over the past ten years, scholars have conducted various studies from different perspectives to test antecedents, consequences, also mediate and moderator effects of FSSB [4] [5] [6].

Drawing on Conservation of Resource theory (COR), Crain (2012) applied FSSB to employees' physical research, and found out that FSSB moderated the association between supervisor positives pill over and employee sleep duration [7]. Samantha and Jonathon (2013) collect data from 628 employees of a health system, using path analytic tests of moderated mediation, provide support for the mediated effect of family-supportive climate on employee work-family conflict (through family supportive supervisor behaviors) [8]. Qing and Zhou (2017) use a 2-wave survey conducted over a 5-month interval, results revealed that FSSB at Time 1 increased bidirectional work-family enrichment and work engagement at Time 2, bidirectional work-family enrichment was found to fully mediate the relationship between FSSB and work engagement [9]. Similarly, Rofcanin et al. (2017) proposed that the positive association between subordinates' perceptions of FSSBs and work engagement was moderated by family supportive organizational culture [10]. Germeys and Sara (2017) argued that family supportive supervisor behaviors moderate the relationship between experiencing home-work conflict and an employee's performance of counterproductive work behavior [11]. In a survey of healthcare workers, Yragui, Demsky, Hammer, Dyck, \& Neradilek (2017) testified the moderating effects of family-supportive supervisor behaviors on the relationship between two types of workplace aggression and employee well-being and work outcomes [12].

Drawing on organizational support theory, Koseek, Pichler, Bodner, \& Hammer (2011) use a meta-analysis method compared the relative influence of 4 types of workplace social support to work-family conflict, found out perceived organizational work-family support partly mediate the relationship between FSSB and work-family conflict [13]. Aryee et al. (2013) use a sample from South Korean organizations, found out that FSSB indirectly positively influence employees' contextual performance and work withdrawal behaviors through psychological path consist of organization-based self-esteem and control over work time [14]. Morris' (2013) research indicates while supervisors' family supportive behaviors benefit to subordinates in theory, but in fact, due to supervisors' poor role modeling, inability to establish priorities and make appropriate applications 
of work/life benefits among employees ineffective, inequitable administrative management of work load and schedules, FSSB doesn't always work [15].

Besides, in order to testify the relationship between FSSB and employees' work, family and wellbeing consequences, affective events theory [16], leader-member exchange theory [17], shared reality theory, social identity theory [18], social exchange theory [19], such classical theories all applied in recent scholars 'empirical research.

Since FSSB has been confirmed positively related to employees' work-family enrichment, job satisfaction, affective commitment, work engagement ... scholars begin to explore these questions "Is FSSB has a same effect on everyone?", "What kind of supervisor characteristic led to FSSB?", "How to increase the probability of supervisors show FSSB?". Two research conduct separately by Clark et al. (2017) [20] and Bosch et al. (2018) [21] revealed FSSB occur differential impact on each gender. Pan (2018) based on role identity theory, made an interesting point that workaholic supervisor will demonstrate FSSB when it's necessary to alleviate subordinate's work-family conflict in turn keeping their work performance [22]. Beyond above empirical research, nearly half of the current studies are focusing on examine the consequences of intervention designed to increase supervisors' use of family supportive supervisor behaviors [23] [24] [25] [26].

To date, there remains vast academic blank field for scholars to explore, previous FSSB research has predominantly studied what effects may bring to employee in work, family and health area, few research tried to figure out the underlying mechanism. Our study based on Chinese contextual, on the one hand we explore how FSSB affect employees' organizational citizen behavior based on Chinese social culture context, on the other hand, on account of FSSB comes from Hammer, a professor of Portland State University, prior researches mainly using sample from "Western Country", our study will be a meaningful attempt figuring out whether this construct will be effective in an underrepresented context.

\section{Theoretical Background and Hypotheses}

\subsection{Family Supportive Supervisor Behaviors and Employees Organizational Citizen Behavior}

Family supportive supervisor behaviors positively related to employees' organizational citizen behavior can be explained by both conservation of resources theory and social exchange theory. First, according to conservation of resources theory, Hobfoll (1989) proposed that individuals will experience strain and further negative work outcomes when they have insufficient resources to cope with demands [27]. FSSB is an important workplace resource for these employees suffering from resources loss spiral both in psychological and practice aspect. Consistent with FSSB construct, emotional support and role modeling behaviors can be critical psychological resources, with supervisor's emotional support, em- 
ployee may feel less stress and pressure in dealing with work-family affairs. Meanwhile instrumental support and creative work-family management can be practice resources which make it possible for employee form a resource gain spiral in turn the retention of other valuable personal resources, namely time and energy which can then be used for organizational citizen behavior.

This proposed relationship can also be explained by social exchange theory and its immediate correlate, organizational support theory [19]. As social exchange theory claimed, because of the norm of reciprocity employee will be grateful and feel oblige to pay back to his/her organizations when FSSB serves as an extra-role behavior which aims to help employee better balance work-family relationship, demonstrated by supervisors, as the organizational representative. Thus, when supervisor use FSSB to help his subordinates, employee will generate perception of organization support and be more forwardly to show organizational citizen behavior towards supervisor or organizational.

Hypothesis 1: FSSB will be positively related to employees' organizational citizen behaviors.

\subsection{Family Supportive Supervisor Behaviors and Family-Like Employee-Organization Relationship}

Drawing on interactive relationship perspective of prior EOR researches, Zhu et al. (2015) contend that compared to western-country individual-centeredness, Chinese workers are situation-centeredness and share a mutual dependence value, familism and collectivism culture decide family be the minimum social unit, employee shares more emotional connection with employer and family. These contextual factors combined led to the third exchange form, beyond economic exchange and social exchange, so called family-like exchange. Family-like employee-organization relationship is a construct developed by Zhu, Long, He, \& Wang in 2015, based on the feature of Chinese collectivistic culture. Zhu et al. define FEOR as a condition that employees and their organizations are oriented to meet each other's needs, and they are integrated in a variety of behaviors careless about requited and self-benefit [28]. Once FEOR formed, employee and their organizations stuck in a highly emotional embedded state, both side follows demands rule, selfless to content with other sides' benefit, these kind of relationship exist in both work and life interface.

Rising in a strong diffusing culture, Chinese tend not to separate their work life and family life, instead, willing to allow others access to their private life space [29]. So we proposed that Chinese employees will be more sensitive and fain to supervisors' family supportive behaviors. In a sense, FSSB beyond general support (mean to help employee improve work performance), when their supervisors do initiatively exhibit such behaviors, employee will regard FSSB as supervisor and organization care for their family to the extent which fulfill their expectation for organizations. Therefore, their perception of insider status will be enhanced; interactive employee-organizational relationship emerged. 
Hypothesis 2: FSSB will be positively related to family-like employee-organization relationship.

\subsection{Family-Like Employee-Organization Relationship and Employees Organizational Citizen Behavior}

According to role identity theory, role identity is one's self-view regarding a specific role, individuals act in ways that are consistent with both who they are and what is important to them [30] [31]. In a family-like employee-organizational relationship, employee received organizational support and concern about their work, family, health both physical and psychological. This relationship status gives employees a sense of belonging, meet their need for affiliation. Family-like employee-organizational relationship help employee form a role identity that they are family members of "big family", naturally, as a family member, not just an "employee", employees will carry different attitudes towards organizations, supervisors, and coworkers, meanwhile accomplish extra-role tasks. So, we firmly believe that in FEOR, employees are more likely to engage in organizational citizen behaviors that improve the wellbeing of the organization.

Hypothesis 3: Family-like employee-organization relationship positively related to employee organizational citizen behavior.

Hypothesis 4: The relationship between FSSB and OCB is mediated by FEOR.

\section{Method}

\subsection{Sample}

In order to break through the restrictions of geographical location and distribute and collect questionnaires as quickly, widely, and high-quality as possible, we took an online approach to conduct this survey. With the help of human resources managers, participants were recruited through convenience sampling between January to February, mainly employment in education, manufacturing, daily chemical, and E-commerce industry to fill a 30minselectronic questionnaire. A total of 400 questionnaires were distributed and 260 were eventually recovered. After removing the invalid questionnaires, 211 valid questionnaires remained, effective recovery rate reaches $52.8 \%$, as an online survey, this has been a very satisfactory result. In the samples we collected, males accounted for $51.15 \%$ and females accounted for $48.85 \%$, average age was 30.1 years old, also $66.36 \%$ of the participants are married or in a relationship while $33.64 \%$ are single.

\subsection{Measures}

- FSSB. To measure FSSB, we used a fourteen-item scale developed by Hammer et al. (2009) [3]. This scale captures the four components of FSSB including emotional support, instrumental support, role modeling behavior, and creative work family management. A Sample item for emotional support is "My supervisor is willing to listen to my problems in juggling work and nonwork life". A sample item for instrumental support is "I can rely on my 
supervisor to make sure my work responsibilities are handled when I have unanticipated non-work demands". A sample item for role modeling behavior is "My supervisor is a good role model for work and nonwork balance". A sample item for creative work family management is "My supervisor is creative in reallocating job duties to help my department work better as a team". The coefficient alpha in the current research was 0.95 .

- FEOR. We used a 5-item scale developed by Zhu et al. (2015) to measure family-like employee-organization relationship [28]. Participants were asked to report their view of individuals' relationship with organizational, whether they hold the opinion being a family member of organization. A sample item is "In my work, all my unit interests are important, because unit interests are closely linked with my interests."The coefficient alpha in the current research was 0.90 .

- OCB. We assessed employee organization citizen behavior using a 10-item scale adopted by Bachrach et al. (2007) [32]. OCB scale consists of two subscales, a sample item for assistant behavior is "If there are employees who can't keep up, I will help". A sample item for citizen ethic is "Participate and actively participate in team meetings". The coefficient alpha in the current research was 0.94 .

- Control Variables. According to previously researches [10] [33] [34], we control gender, age, marital status, tenure \& fertility status such variables may have an effect on our consequence variable.

\subsection{Confirmatory Factor Analysis}

Confirmatory factor analysis was conducted to evaluate the distinctiveness and convergence of the study variables. The results of confirmatory factor analysis are presented in Table 1 and show that the hypothesized three factor model demonstrates a more acceptable fit to the data $\left(\chi^{2}=838.468\right.$, df $=369$, CFI $=$ 0.912 , TLI $=0.903$, RMSEA $=0.078$, SRMR $=0.057$ ) than one factor model and two factor model. Results show that these three variables have good discriminant validity.

Table 1. Confirmatory factor analysis.

\begin{tabular}{ccccccc}
\hline Model & $\chi^{2}$ & df & CFI & TLI & SRMR & RMSEA \\
\hline 1. FSSB, FEOR, OCB & 838.468 & 369 & 0.912 & 0.903 & 0.057 & 0.078 \\
2. FSSB + FEOR, OCB & 1337.991 & 371 & 0.819 & 0.802 & 0.100 & 0.111 \\
3. FSSB, FEOR + OCB & 1230.306 & 371 & 0.839 & 0.824 & 0.077 & 0.105 \\
4. FSSB + OCB, FEOR & 1803.038 & 371 & 0.732 & 0.707 & 0.116 & 0.135 \\
5. FSSB + FEOR + OCB & 2147.413 & 372 & 0.668 & 0.637 & 0.124 & 0.150 \\
\hline
\end{tabular}

Note: $\mathrm{N}=211$. FSSB = Family supportive supervisor behaviors, FEOR = Family-like employee-organization relationship, OCB = Organizational citizenship behavior. CFI is the comparative fit index; TLI is the Tucker-Lewis index; SRMR is the standardized root-mean-square residual; RMSEA is the root-mean-square error of approximation. 


\section{Results}

Descriptive statistics, correlations, and scale reliabilities among the variables of interest are displayed in Table 2.

From Table 2, it can be seen that our hypothesis has been initially verified. Finally, as we proposed that FSSB is positively related to OCB $(r=0.526, p<$ 0.01 ), hypothesis 1 has been confirmed; FSSB is positively related to FEOR ( $\mathrm{r}=$ $0.516, \mathrm{p}<0.01)$, hypothesis 2 verified; FEOR also positively related to OCB ( $\mathrm{r}=$ $0.615, \mathrm{p}<0.01)$, means our hypothesis 3 also correct.

As Table 3 demonstrates, to further verify our hypothesis, we built model 1 5 to test our hypothesis. From above figure, Model 2 confirmed that FSSB is positively related to FEOR $(\beta=0.500, \mathrm{p}<0.001)$, Model 4 confirmed that FSSB is positively related to OCB $(\beta=0.499, \mathrm{p}<0.001)$, in model 5 , we found that when we add the control variable and FSSB, FEOR to the regression test at the same time, the positively relationship between FEOR and OCB was significant, but there is still a significantly relationship between FSSB and OCB which means FEOR partly mediated the relationship between FSSB and employee OCB, our hypothesis 4 is significant.

\section{Discussion}

According to the statistics come from web of science, work-family scholars are increasingly interested in FSSB, since this construct has been proposed, articles published on related topics have increased year by year, see Figure 1. To date, along with conducting of a series of previously researches, our understanding of this concept has been extremely enriched. Individual-level factors (e.g., work-family interference, social identification, gender roles), contextual-level factors (e.g., family supportive organizational culture, top management openness) and leader-member exchange quality have been confirmed raising supervisors' FSSB [35]; meanwhile, work-related outcomes (e.g., turnover intentions, job satisfaction, work engagement), family-related outcomes (e.g. marriage satisfaction,

Table 2. Descriptive and correlations.

\begin{tabular}{|c|c|c|c|c|c|c|c|c|c|c|}
\hline Variables & Mean & SD & 1 & 2 & 3 & 4 & 5 & 6 & 7 & 8 \\
\hline 1. Gender & 1.490 & 0.501 & & & & & & & & \\
\hline 2. Age & 2.100 & 1.510 & $0.225^{\star *}$ & & & & & & & \\
\hline 3. Marriage & 2.030 & 0.847 & $0.265^{\star *}$ & $0.593^{\star *}$ & & & & & & \\
\hline 4. Tenure & 1.740 & 1.242 & $0.225^{\star *}$ & $0.930^{\star *}$ & $0.564^{\star *}$ & & & & & \\
\hline 5. Children & 1.750 & 0.432 & $-0.146^{\star}$ & $-0.488^{\star *}$ & $-0.628^{\star x}$ & $-0.500^{\star *}$ & & & & \\
\hline 6. FSSB & 3.639 & 0.900 & -0.127 & -0.133 & -0.086 & -0.094 & $0.177^{\star \star}$ & $(0.955)$ & & \\
\hline 7. FEOR & 4.028 & 0.814 & $-0.234^{\star *}$ & 0.076 & -0.055 & 0.111 & 0.092 & $0.516^{\star *}$ & $+(0.904)$ & \\
\hline 8. OCB & 4.038 & 0.726 & $-0.151^{*}$ & 0.004 & -0.015 & 0.052 & 0.127 & $0.526^{\star *}$ & $+0.615^{\star *}$ & $(0.946)$ \\
\hline
\end{tabular}

Note: $\mathrm{N}=211$. Values in parentheses and on the diagonal represent Cronbach's alpha. Gender coded as $1=$ male, 2 = female. Marriage coded as $1=$ single, $2=$ in a relationship, $3=$ married. Tenure coded as $1=$ less than 5 years, $2=5-10$ years, $3=11-15$ years, $4=16-20$ years, $5=$ more than 20 years. ${ }^{\star} \mathrm{p}<0.05 .{ }^{*} \mathrm{p}<0.01$. 
Table 3. Regression analysis results

\begin{tabular}{cccccc}
\hline Variables & \multicolumn{2}{c}{ FEOR } & OCB & \\
\hline & Model 1 & Model 2 & Model 3 & Model 4 & Model 5 \\
\hline Constant & $3.833^{* * *}$ & $2.484^{* * *}$ & $3.348^{* * *}$ & $2.147^{* * *}$ & $1.132^{* *}$ \\
Gender & $-0.261^{* * *}$ & $-0.204^{* *}$ & $-0.176^{*}$ & -0.118 & -0.025 \\
Age & -0.127 & 0.045 & -0.330 & -0.158 & -0.178 \\
Marriage & -0.020 & -0.078 & 0.128 & 0.069 & 0.105 \\
Tenure & $0.385^{*}$ & 0.238 & $0.449^{*}$ & 0.303 & 0.194 \\
Children & $0.172^{*}$ & 0.066 & $0.245^{* *}$ & 0.139 & 0.109 \\
FSSB & & $0.500^{* * *}$ & & $0.499^{* * *}$ & $0.270^{* * *}$ \\
FEOR & & & & & $0.458^{* * *}$ \\
F-statistic & $5.119^{* * *}$ & $17.995^{* * *}$ & $3.467^{* *}$ & $15.424^{* * *}$ & $23.638^{* * *}$ \\
$\Delta \mathrm{R}^{2}$ & 0.111 & 0.235 & 0.078 & 0.234 & 0.137 \\
$\mathrm{R}^{2}$ & 0.089 & 0.327 & 0.078 & 0.312 & 0.449 \\
\hline
\end{tabular}

Note: $\mathrm{N}=2$ 211. Standardized regression coefficients are presented. ${ }^{*} \mathrm{p}<0.05 .{ }^{* *} \mathrm{p}<0.01 .{ }^{* * *} \mathrm{p}<0.001$.

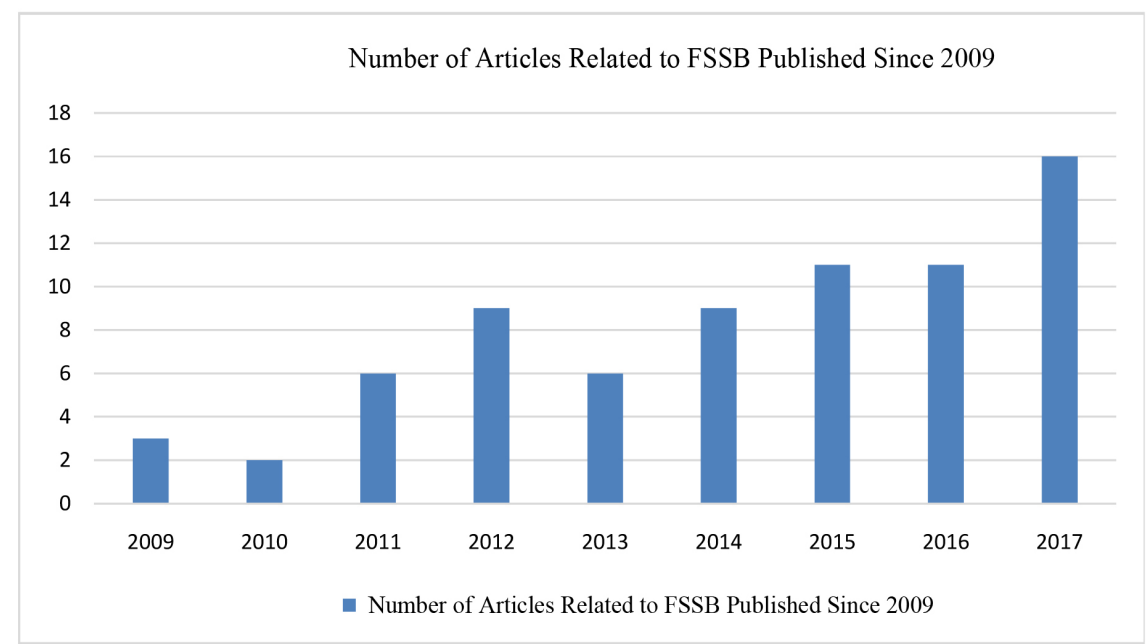

Figure 1. FSSB theme related articles published over the years. Source: Web of Science (http://wcs.webofknowledge.com/RA/analyze.do).

work-family enrichment) and health-related outcomes (e.g. blood pressure, sleep duration, pressure) also have been proved connected to FSSB [24] [36].

\subsection{Theoretical Implications and Practical Implications}

Obviously, there still remaining some deficiencies among FSSB research. First, above research results mostly based on Western-context, whether such results still significantly in a differently context need for test; secondly, existing researches testified FSSB will evoke employee' OCB [22] [37], but the underlying path hasn't been revealed; thirdly, FSSB construct and measure scale need more empirical research test. Our study based on Chinese unique culture context, collect research data from 211 white-collar workers living in different megacities of 
China, results indicate that FSSB still works in Eastern-context, the measure scale developed by Hammer et al. (2009) presents considerable reliability and validity. Besides, by using empirical research method, combined with Chinese diffusing and collective culture feature, we found a special underlying path between FSSB and employee OCB that is family-like employee-organization relationship, but the mediated effect was partly significant, there still other paths among FSSB and OCB to be excavated.

Practically, our findings can bring some inspirations to Chinese business managers. Family supportive supervisor behaviors are not only beneficial to the personal interests of employees, but also help the development of the organization. Supervisor' family supportive behaviors will make it easier for employee and organization form a kind of family-like relationship, in turn, help employee establish a family member role identification and exhibits organization citizen behaviors. Thus, employer should dedicate to build a family supportive organizational culture, encourage supervisors exhibiting FSSB, eventually, FSSB will help organizations and employees achieve win-win results.

\subsection{Limitations and Conclusions}

To be frankly, though our research has made some contributions to theory and practice, there are also many things that can be improved. First of all, our measurements were conducted at the individual level of the staff and there was no matching measurement for supervisors and employees. Future research can measure the effectiveness of the FSSB at individual, supervisor, and organizational levels. In terms of sample selection, some working hours are difficult to arrange flexibly, and for special groups with prominent work-family conflicts, such as teachers, policemen, and sanitation workers, whether the FSSB is effective may become the theoretical boundary of the FSSB. Moreover, our study simply tested the mediating effect of the model. The results show that the FSSB has other paths to affect the OCB. In addition, we do not consider too much of the moderating variables, and the power distance and family responsibility such other factors may affect employee's perception of FSSB, which needs further study. Work-family relations have always been one of the topics of study in Western academic circles. While pursuing high work performance, both theorists and practitioners have paid enough attention to employees and families. Unfortunately, Chinese academic circles and enterprises Management's attention and research on individual employees and families have been on the fringes.

As the new generation of employees gradually becomes the pillar of the company, they are increasingly pursuing their personal happiness and ideals, and they also yearn for the company's concern for individuals and families. The FSSB and other work-family research themes deserve more attention.

\section{References}

[1] Casper, W.J., Fox, K.E., Sitzmann, T.M. and Landy, A.L. (2004) Supervisor Referrals 
to Work-Family Programs. Journal of Occupational Health Psychology, 9, 136-151. https://doi.org/10.1037/1076-8998.9.2.136

[2] Rooney, J.A. and Gottlieb, B.H. (2007) Development and Initial Validation of a Measure of Supportive and Unsupportive Managerial Behaviors. Journal of Vocational Behavior, 71, 186-203. https://doi.org/10.1016/j.jvb.2007.03.006

[3] Hammer, L.B., Kossek, E.E., Yragui, N.L., Bodner, T.E. and Hanson, G.C. (2009) Development and Validation of a Multidimensional Measure of Family Supportive Supervisor Behaviors (FSSB). Journal of Management, 35, 837-856. https://doi.org/10.1177/0149206308328510

[4] Rooney, J.A., Gottlieb, B.H. and Newby-Clark, I.R. (2009) How Support-Related Managerial Behaviors Influence Employees an Integrated Model. Journal of Managerial Psychology, 24, 410-427. https://doi.org/10.1108/02683940910959744

[5] Crain, T.L., Hammer, L.B., Bodner, T., Kossek, E.E., Moen, P., Lilienthal, R. and Buxton, O.M. (2014) Work-Family Conflict, Family-Supportive Supervisor Behaviors (FSSB), and Sleep Outcomes. Journal of Occupational Health Psychology, 19, 155-167. https://doi.org/10.1037/a0036010

[6] Kossek, E.E., Lewis, S. and Hammer, L.B. (2010) Work-Life Initiatives and Organizational Change: Overcoming Mixed Messages to Move from the Margin to the Mainstream. Human Relations, 63, 3-19. https://doi.org/10.1177/0018726709352385

[7] Crain, T.L., Hammer, L.B., Bodner, T.E. and Buxton, O.M. (2012) The Crossover Effects of Supervisor Work-Family Positive Spillover on Employee Sleep Deficiency: Moderating Effects of Family Supportive Supervisor Behaviors (FSSB). Sleep, 35, A84-A84.

[8] Paustian-Underdahl, S.C. and Halbesleben, J.R.B. (2014) Examining the Influence of Climate, Supervisor Guidance, and Behavioral Integrity on Work-Family Conflict: A Demands and Resources Approach. Journal of Organizational Behavior, 35, 447-463. https://doi.org/10.1002/job.1883

[9] Qing, G.X. and Zhou, E.H. (2017) Bidirectional Work-Family Enrichment Mediates the Relationship between Family Supportive Supervisor Behaviors and Work Engagement. Social Behavior and Personality, 45, 299-308. https://doi.org/10.2224/sbp.6023

[10] Rofcanin, Y., Heras, M.L. and Bakker, A.B. (2017) Family Supportive Supervisor Behaviors and Organizational Culture: Effects on Work Engagement and Performance. Journal of Occupational Health Psychology, 22, 207-217. https://doi.org/10.1037/ocp0000036

[11] Germeys, L. and De Gieter, S. (2017) Clarifying the Dynamic Interrelation of Conflicts between the Work and Home Domain and Counterproductive Work Behavior. European Journal of Work and Organizational Psychology, 26, 457-467. https://doi.org/10.1080/1359432X.2017.1314266

[12] Yragui, N.L., Demsky, C.A., Hammer, L.B., Van Dyck, S. and Neradilek, M.B. (2017) Linking Workplace Aggression to Employee Well-Being and Work: The Moderating Role of Family-Supportive Supervisor Behaviors (FSSB). Journal of Business and Psychology, 32, 179-196. https://doi.org/10.1007/s10869-016-9443-Z

[13] Kossek, E.E., Pichler, S., Bodner, T. and Hammer, L.B. (2011) Workplace Social Support and Work-Family Conflict: A Meta-Analysis Clarifying the Influence of General and Work-Family-Specific Supervisor and Organizational Support. Personnel Psychology, 64, 289-313. https://doi.org/10.1111/j.1744-6570.2011.01211.x

[14] Aryee, S., Chu, C.W.L., Kim, T.Y. and Ryu, S. (2013) Family-Supportive Work Environment and Employee Work Behaviors: An Investigation of Mediating Mechan- 
isms. Journal of Management, 39, 792-813.

https://doi.org/10.1177/0149206311435103

[15] Morris, M.L. (2012) Unleashing Human Expertise through Work/Life Initiatives. Human Resource Development Quarterly, 23, 427-439.

https://doi.org/10.1002/hrdq.21145

[16] Mills, M.J., Matthews, R.A., Henning, J.B. and Woo, V.A. (2014) Family-Supportive Organizations and Supervisors: How Do They Influence Employee Outcomes and for Whom? International Journal of Human Resource Management, 25, 1763-1785. https://doi.org/10.1080/09585192.2013.860387

[17] Litano, M.L., Major, D.A., Landers, R.N., Streets, V.N. and Bass, B.I. (2016) A Meta-Analytic Investigation of the Relationship between Leader-Member Exchange and Work-Family Experiences. Leadership Quarterly, 27, 802-817. https://doi.org/10.1016/j.leaqua.2016.06.003

[18] Basuil, D.A., Manegold, J.G. and Casper, W.J. (2016) Subordinate Perceptions of Family-Supportive Supervision: The Role of Similar Family-Related Demographics and Its Effect on Affective Commitment. Human Resource Management Journal, 26, 523-540. https://doi.org/10.1111/1748-8583.12120

[19] Eisenberger, R., Huntington, R., Hutchison, S. and Sowa, D. (1986) Perceived Organizational Support. Journal of Applied Psychology, 71, 500-507. https://doi.org/10.1037/0021-9010.71.3.500

[20] Clark, M.A., Rudolph, C.W., Zhdanova, L., Michel, J.S. andBaltes, B.B. (2017) Organizational Support Factors and Work-Family Outcomes: Exploring Gender Differences. Journal of Family Issues, 38, 1520-1545.

https://doi.org/10.1177/0192513X15585809

[21] Bosch, M.J., Heras, M.L., Russo, M., Rofcanin, Y. and Grau, M.G.I. (2018) How Context Matters: The Relationship between Family Supportive Supervisor Behaviours and Motivation to Work Moderated by Gender Inequality. Journal of Business Research, 82, 46-55. https://doi.org/10.1016/j.jbusres.2017.08.026

[22] Pan, S.Y. (2018) Do Workaholic Hotel Supervisors Provide Family Supportive Supervision? A Role Identity Perspective. International Journal of Hospitality Management, 68, 59-67. https://doi.org/10.1016/j.ijhm.2017.09.013

[23] Shockley, K.M. and Allen, T.D. (2013) Episodic Work-Family Conflict, Cardiovascular Indicators, and Social Support: An Experience Sampling Approach. Journal of Occupational Health Psychology, 18, 262-275. https://doi.org/10.1037/a0033137

[24] Kelly, E.L., Moen, P., Oakes, J.M., Fan, W., Okechukwu, C., Davis, K.D., Casper, L.M., et al. (2014) Changing Work and Work-Family Conflict: Evidence from the Work, Family, and Health Network. American Sociological Review, 79, 485-516. https://doi.org/10.1177/0003122414531435

[25] Leschyshyn, A. and Minnotte, K.L. (2014) Professional Parents' Loyalty to Employer: The Role of Workplace Social Support. Social Science Journal, 51, 438-446. https://doi.org/10.1016/j.soscij.2014.04.003

[26] Hammer, L.B., Truxillo, D.M., Bodner, T., Rineer, J., Pytlovany, A.C. and Richman, A. (2015) Effects of a Workplace Intervention Targeting Psychosocial Risk Factors on Safety and Health Outcomes. Biomed Research International, 2015, Article ID: 836967. https://doi.org/10.1155/2015/836967

[27] Hobfoll, S.E. (1989) Conservation of Resources. A New Attempt at Conceptualizing Stress. American Psychologist, 44, 513-524. https://doi.org/10.1037/0003-066X.44.3.513

[28] Zhu, S.L., Long, L.R., He, W. and Wang, Z.J. (2015) Beyond the Instrumental Ex- 
change, the Family-Like Employee-Organization Relationship in Chinese Firms: Theory Building and Empirical Investigation. Management World, 11, 119-132.

[29] Ferris, G.R., et al. (2009) Relationships at Work: Toward a Multidimensional Conceptualization of Dyadic Work Relationships. Journal of Management, 35, 1379-1403. https://doi.org/10.1177/0149206309344741

[30] Burke, P.J. and Reitzes, D.C. (1981) The Link between Identity and Role Performance. Social Psychology Quarterly, 44, 83-92. https://doi.org/10.2307/3033704

[31] Callero, P.L. (1985) Role-Identity Salience. Social Psychology Quarterly, 48, 203-215. https://doi.org/10.2307/3033681

[32] Bachrach, D.G., Wang, H., Bendoly, E. and Zhang, S. (2007) Importance of Organizational Citizenship Behavior for Overall Performance Evaluation: Comparing the Role of Task Interdependence in China and the USA. Management and Organization Review, 3, 255-276. https://doi.org/10.1111/j.1740-8784.2007.00071.x

[33] Odle-Dusseau, H.N., Britt, T.W. and Greene-Shortridge, T.M. (2012) Organizational Work-Family Resources as Predictors of Job Performance and Attitudes: The Process of Work-Family Conflict and Enrichment. Journal of Occupational Health Psychology, 17, 28-40. https://doi.org/10.1037/a0026428

[34] Matthews, R.A. and Toumbeva, T.H. (2015) Lagged Effects of Family-Supportive Organization Perceptions and Supervision in Relation to Generalized Work-Related Resources. Journal of Occupational Health Psychology, 20, 301-313. https://doi.org/10.1037/a0038377

[35] Straub, C. (2012) Antecedents and Organizational Consequences of Family Supportive Supervisor Behavior: A Multilevel Conceptual Framework for Research. $\mathrm{Hu}$ man Resource Management Review, 22, 15-26. https://doi.org/10.1016/j.hrmr.2011.08.001

[36] Hammer, L.B., Kossek, E.E., Bodner, T. and Crain, T. (2013) Measurement Development and Validation of the Family Supportive Supervisor Behavior Short-Form (FSSB-SF). Journal of Occupational Health Psychology, 18, 285-296. https://doi.org/10.1037/a0032612

[37] Wang, P., Walumbwa, F.O., Wang, H. and Aryee, S. (2013) Unraveling the Relationship between Family-Supportive Supervisor and Employee Performance. Group \& Organization Management, 38, 258-287. https://doi.org/10.1177/1059601112472726 